\title{
Perancangan Media Interaktif Buku Ilustrasi Menggunakan Augmented Reality
}

\author{
Raham Sutan Iliyas $^{{ }^{*}}$, Eva Handriyantini ${ }^{2}$ \\ ${ }^{1,2}$ Sekolah Tinggi Informatika dan Komputer Indonesia, Malang, Jawa Timur \\ Email: ${ }^{1 *}$ raham.iliyas@gmail.com, ${ }^{2}$ eva@ stiki.ac.id
}

(Naskah masuk: 15 Jul 2021, direvisi: 25 Okt 2021, diterima: 1 Nov 2021)

\begin{abstract}
Abstrak
Media interaktif adalah pemanfaatan komputer untuk membuat dan menggabungkan teks, grafik, audio, gambar bergerak dengan menggunakan link dan tool yang memungkinkan pemakai melakukan navigasi, berintraksi, berkreasi, dan berkomunikasi dengan media yang ada. Augmented Reality adalah teknologi yang menggabungkan dunia nyata dengan informasi yang berbentuk objek virtual. Teknologi Augmented Reality adalah teknologi yang diterapkan pada beberapa platform, salah satunya adalah platform Android. Sedangkan buku ilustrasi adalah buku yang menampilkan hasil visualisasi dari suatu tulisan dengan teknik drawing, lukisan, fotografi, atau teknik seni rupa lainnya yang lebih menekankan hubungan subjek dengan tulisan. Tujuan aplikasi ini adalah menerapakan Augmented Reality pada buku illustrasi sehingga membentuk media interaktif untuk memberikan rasa menarik dan menyenangkan dalam belajar mengenai informasi baru pada buku illustrasi. Aplikasi ini juga memberikan fitur game sehingga pengguna dapat mengulas kembali materi yang telah diajarkan pada buku illustrasi. Aplikasi ini menggunakan platform Android dengan menggunakan software pengembang Unity dan Vuforia SDK.
\end{abstract}

Kata Kunci: Android, Augmented Reality, Buku Illustrasi, Media Interaktif.

\section{Designing Illustration Books Interactive Media Using Augmented Reality}

\begin{abstract}
Interactive media is the use of computers to create and combine text, graphics, audio, moving images by using links and tools that allow users to navigate, interact, create and communicate with existing media. Augmented Reality is a technology that combines the real world with information in the form of virtual objects. Augemented reality is a technology that is applied to several platforms, one of which is the Android platform. Meanwhile, an illustration book is a book that displays the visualization of a writing using drawing, painting, photography, or other art techniques that emphasize the relationship between the subject and the writing. The purpose of this application is to apply Augmented Reality to illustration books so as to form interactive media to provide a sense of interest and fun in learning new information in illustration books. This application also provides a game feature so that users can review the material that has been taught in the illustration book. This application uses the Android platform using the Unity and Vuforia SDK developer software.
\end{abstract}

Keywords: Android, Augmented Reality, Illustration Book, Interactive Media.

\section{PENDAHULUAN}

Buku ilustrasi adalah buku yang menampilkan hasil visualisasi dari suatu tulisan dengan teknik drawing, lukisan, fotografi, atau teknik seni rupa lainnya yang lebih menekankan hubungan subjek dengan tulisan [1]. Buku ilustrasi menjadi salah satu media penyampaian informasi yang sering digunakan di antara media lainnya. Media penyampai informasi rata-rata hanyalah berbentuk teks dan gambar saja, yang seharusnya dapat dikembangkan lebih lanjut dengan teknologi yang ada. Perkembangan teknologi memungkinkan terciptanya media interaktif baru dari buku ilustrasi. 
Media interaktif adalah pemanfaatan komputer untuk membuat dan menggabungkan teks, grafik, audio, gambar bergerak dengan menggunakan link dan tool yang memungkinkan pemakai melakukan navigasi, berintraksi, berkreasi, dan berkomunikasi dengan media yang ada [2]. Media interaktif dapat memberikan nilai tambah dalam penyampaian informasi dengan cara memberikan kesempatan pengguna berinteraksi secara langsung untuk mendapatkan informasi yang diinginkan. Augmented Reality adalah salah satu media interaktif yang terus berkembang dan dapat diaplikasikan pada berbagai media, salah satunya adalah buku ilustrasi.

Augmented Reality adalah teknologi media interaktif yang terus berkembang, menawarkan interaktivitas tambahan pada objek dunia nyata, dan dapat memberikan informasi secara langsung melalui aplikasi digital. Augmented Reality merupakan aplikasi penggabungan dunia nyata dengan dunia maya dalam bentuk dua dimensi maupun tiga dimensi yang diproyeksikan dalam sebuah lingkungan nyata pada waktu yang bersamaan [3]. Dengan berkembangnya teknologi Augmented Reality semakin banyak juga nilai interaktivitas yang dapat ditawarkan, berawal dari hanya menampilkan objek secara digital hingga dapat bermain permainan digital menggunakan Augmented Reality. Augmented Reality dapat menggabungkan buku ilustrasi dengan media interaktif dengan cara menyatukan aplikasi virtual dengan media buku sehingga buku menampilkan informasi yang dapat memberikan nilai interaktivitas dan menarik minat pembaca. Dengan demikian Augmented Reality adalah salah satu media interaktif yang cocok untuk edukasi dan membantu penyampaian informasi secara interaktif [4].

Perkembangan teknologi memungkinkan menggabungkan media buku ilustrasi dengan media interaktif Augmented Reality. Remaja sebagai target audience menyukai kombinasi media ini karena selain buku dilengkapi dengan ilustrasi menarik ditambah pula dengan fitur AR yang membuat lebih interaktif [5][6]. Maka dari itu dirancanglah aplikasi AR media interaktif buku illustrasi menggunakan Augmented Reality. Penerapan Augmented Reality pada buku ilustrasi akan memberikan pengalaman baru dalam menerima informasi dengan cara berinteraksi secara langsung dengan buku yang ada melalui Augmented Reality.

\section{ANALISIS DAN PERANCANGAN}

\section{A. Analisis Masalah}

Aplikasi edukasi seks sangat susah ditemukan. Kebanyakan dari aplikasi yang ada hanya dari luar negeri dan sebagian besar dari aplikasi tersebut diperuntukkan untuk dewasa. Dari aplikasi yang sudah penulis kumpulkan dan analisis sebelumnya pada Tabel 1, aplikasi edukasi yang seharusnya dikembangkan agar menjadi menarik dan interaktif untuk menarik minat anak-anak dan remaja malah memberikan hasil yang kurang menarik dan kurang sekali faktor interaktifnya, seperti aplikasi Augmented Reality yang hanya menampilkan objek dan hanya bisa diputar-putar. Remaja Indonesia membutuhkan edukasi seks sehingga kasus penyakit menular seks seperti AIDS dan HIV tidak semakin banyak.

Tabel 1. Tabel Aplikasi Serupa

\begin{tabular}{|c|c|c|}
\hline Nama & Penerbit & Kekurangan \\
\hline $\begin{array}{l}\text { Sex } \\
\text { Education }\end{array}$ & $\begin{array}{l}\text { Mayank } \\
\text { Singh }\end{array}$ & $\begin{array}{l}\text { - Berbentuk teks dan gambar } \\
\text { - Terlihat seperti aplikasi } \\
\text { yang hanya berisi halaman } \\
\text { halaman saja seperti buku }\end{array}$ \\
\hline $\begin{array}{l}\text { Complete Sex } \\
\text { Education } \\
\text { Guide }\end{array}$ & $\begin{array}{l}\text { Suniyal } \\
\text { World }\end{array}$ & $\begin{array}{l}\text { - Informasi hanya berbentuk } \\
\text { teks dan gambar }\end{array}$ \\
\hline Amaze & Amaze & $\begin{array}{l}\text { - Kebanyakan konten hanya } \\
\text { diarahkan ke video di } \\
\text { Media Platform Video }\end{array}$ \\
\hline $\begin{array}{l}\text { My Sex } \\
\text { Doctor Lite }\end{array}$ & $\begin{array}{l}\text { MYSD } \\
\text { LTD }\end{array}$ & $\begin{array}{l}\text { - Hanya berisikan teks } \\
\text { informasi }\end{array}$ \\
\hline $\begin{array}{l}\text { Puberty } \\
\text { Explained for } \\
\text { Kids }\end{array}$ & Fas F & $\begin{array}{l}\text { - Hanya sekedar buku yang } \\
\text { dijadikan aplikasi }\end{array}$ \\
\hline
\end{tabular}

Hasil wawancara penulis dengan Ketua Insan GenRe Jombang menejelaskan bahwa edukasi seks penting karena dengan edukasi yang tepat, dari yang sebelumnya menganggap bahwa seks adalah yang tabu dan menjadi sebuah candaan, remaja jadi mengenal tentang bagaimana merawat organ reproduksi yang dimiliki dan remaja lebih menjaga diri. Kurangnya media dan aplikasi yang mengikuti kemajuan teknologi menyebabkan sedikitnya media yang dapat diakses secara cepat dan mudah dalam menyampaikan edukasi seks. Remaja yang tidak tahu tentang topik tersebut memiliki kemungkinan untuk melakukan seks dan tidak dengan cara yang aman. Tanpa adanya pengetahuan tentang seks yang aman maka remaja akan lebih rentan untuk hamil dibawah umur dan juga terkena penyakit menular seks [7].

Aplikasi edukasi yang interaktif dan menarik menggunakan Augmented Reality kurang diimplementasikan di Indonesia sehingga edukasi yang seharusnya tersampaikan dengan baik, menarik, dan menyenangkan menjadi kurang maksimal [8].

\section{B. Pemecahan Masalah}

Berdasarkan analisis masalah tersebut, agar tercipta sebuah media untuk menyampaikan topik seks yang menarik dan interaktif maka dibuatlah media interaktif buku illustrasi menggunakan Augmented Reality sebagai media penyampai edukasi seks yang menjadi solusi dari permasalahan di atas. Aplikasi ini menggunakan platform mobile dan juga media buku sehingga dapat diakses dengan mudah. Aplikasi Augmented Reality ini akan memberikan nilai interaktivitas tambahan melalui interaksi yang terjadi pada informasi yang ada. Dengan adanya games sebagai fitur tambahan pada aplikasi ini pengguna juga akan dapat mengulas topik yang ada dengan cara yang menarik dan menyenangkan.

Dengan adanya aplikasi ini diharapkan topik edukasi seks dapat dengan mudah disampaikan oleh pengguna seperti orang tua atau instansi, dan juga menarik minat remaja untuk belajar 
agar dapat mencegah penyakit menular seks dan juga mengurangi angka kehamilan dibawah umur.

\section{Kelebihan Pemecahan Masalah}

Adanya aplikasi Augmented Reality untuk menyampaikan topik seks di Indonesia dapat memberikan pengalaman baru dan juga membuat remaja tidak malu untuk membahas topik tersebut. Pengguna akan mendapatkan informasi tentang perkembangan tubuh manusia setelah pubertas, penyakit menular seks, cara pencegahan penyakit menular seks, dan cara pencegahan hamil dibawah umur. Pengguna dapat melihat informasi dengan cara berinteraksi langsung dengan media interaktif melalui Augmented Reality. Pengguna dapat memainkan board game dan diberikan pertanyaan mengenai topik dan informasi yang sudah disampaikan melalui buku maupun Augmented Reality sehingga pengguna dapat mengulas tentang materi yang sudah dibaca [9].

Unity Game Engine dan Vuforia SDK adalah alat yang akan digunakan oleh penulis untuk pengembangan. Dua alat pengembang tersebut mendukung platform Android yang akan digunakan oleh penulis dan juga mendukung perangkat yang lama, sehingga untuk menggunakan aplikasi tidak perlu menggunakan perangkat baru. Vuforia menggunakan marker based sehingga cocok dengan media yang penulis gunakan yaitu buku illustrasi [10][11][2].

\section{Perancangan Aplikasi}

\section{Buku Ilustrasi "Sex Education is not Taboo"}

Media buku illustrasi yang akan digunakan sebagai objek Augmented Reality ialah buku "Sex Education is not Taboo". Buku ini berisi tentang edukasi seks yang membantu remaja untuk mempelajari topik tersebut tanpa merasa takut dan tabu. Buku ini juga dapat digunakan sebagai media bantu untuk orang tua dan guru membekali anak remaja terkait edukasi seks yang aman dan benar. Buku illustrasi ini berbasis dari modul BKKBN yang berjudul "Rencanakan Masa Depanmu" [7].

Rancangan buku ilustrasi yang dilakukan menggunakan storyboard sebagaimana pada Gambar 1 dan Gambar 2, yang memuat materi pembahasan yang berkaitan dengan pendidikan seks bagi remaja.

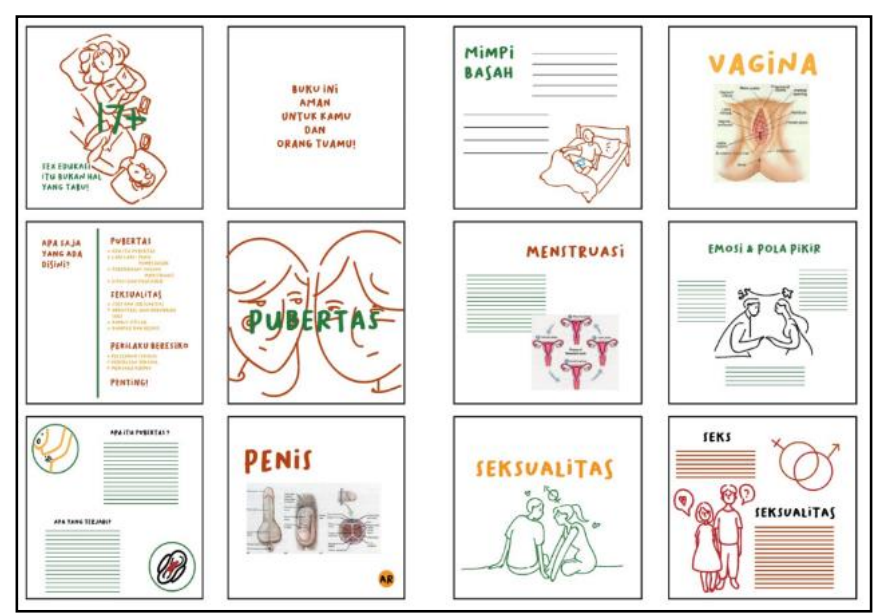

Gambar 1. Storyboard Untuk Buku Illustrasi "Sex Education is not Taboo" - Bagian 1
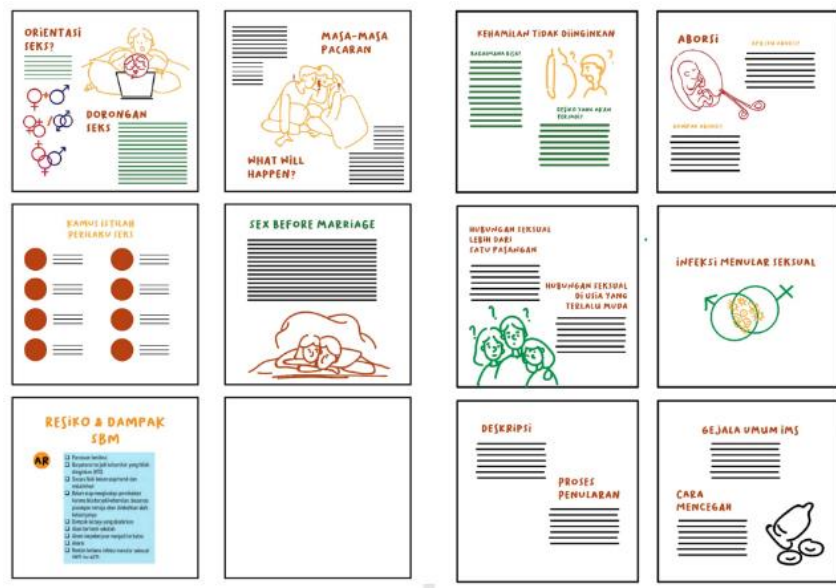

Gambar 2. Storyboard untuk Buku Illustrasi "Sex Education is not Taboo" - Bagian 2

\section{Use Case Diagram}

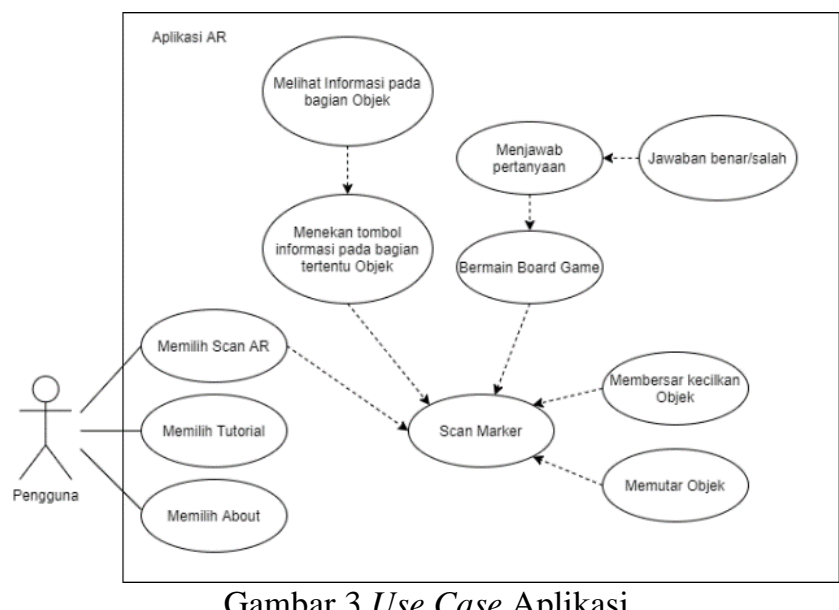

Use case pada Gambar 3 menggambarkan fitur apa saja yang dapat digunakan oleh pengguna. Fitur-fitur yang ada pada aplikasi dapat dideskripsikan sebagai berikut:

Pengguna sebagai aktor dapat mengakses:

- Dapat melihat tutorial cara penggunaan aplikasi

- Dapat melihat informasi tentang aplikasi yang berisi informasi pengembang

- Dapat mengakses fitur Scan AR

Fitur Scan $A R$ memiliki beberapa fitur lain yang dapat diakses oleh aktor, diantaranya :

- Dapat melihat informasi yang ditampilkan oleh objek

- Dapat membesarkan dan mengecilkan ukuran objek

- Dapat memutar orientasi objek

- Dapat menerima informasi dari bagian-bagian tertentu objek dengan cara menekan bagian tersebut

- Dapat bermain board game Pada fitur board game aktor dapat mengakses :

- Dapat menjawab pertanyaan / quiz

- Jawaban benar atau salah

\section{Flowchart}

Flowchart Scan AR 
Proses Scan AR yang digambarkan pada Gambar 4 dapat diuraikan dan dijelaskan seperti berikut. Pertama pada tampilan AR Camera aplikasi akan mencari marker yang sesuai. Setelah marker ditemukan maka akan di-scan dan ditampilkan objek yang sesuai. Apabila pengguna melakukan interaksi sesuai dengan objek maka akan ditampilkan informasi yang sesuai dengan tombol. Apabila pengguna keluar maka proses akan selesai.

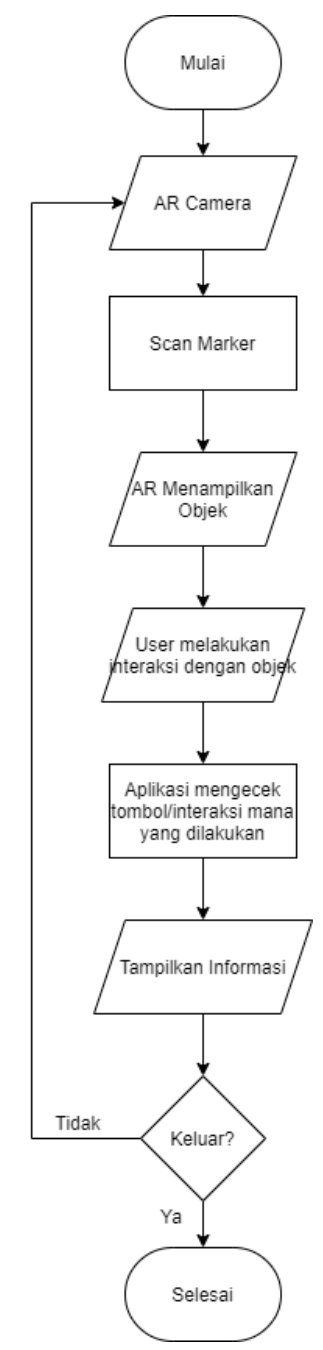

Gambar 4. Flowchart Scan AR

\section{Flowchart Games}

Alur proses games yang ditampilkan pada Gambar 5 dapat dijabarkan dan dijelaskan sebagai berikut. Pertama kamera $A R$ akan mencari marker Game dan akan memindai marker tersebut. Kemudian kamera $A R$ akan menampilkan roda games, dan juga tombol untuk memutar roda. Ketika tombol putar roda ditekan maka aplikasi akan mengacak putaran roda. Setelah berhenti aplikasi akan mengacak pertanyaan sesuai berhentinya roda. Pertanyaan akan ditampilkan dan pengguna bisa menjawab. Apabila jawaban salah maka akan tampil objek salah. Apabila jawaban benar maka akan tampil objek benar. Ketika pengguna keluar dari aplikasi maka proses akan selesai.

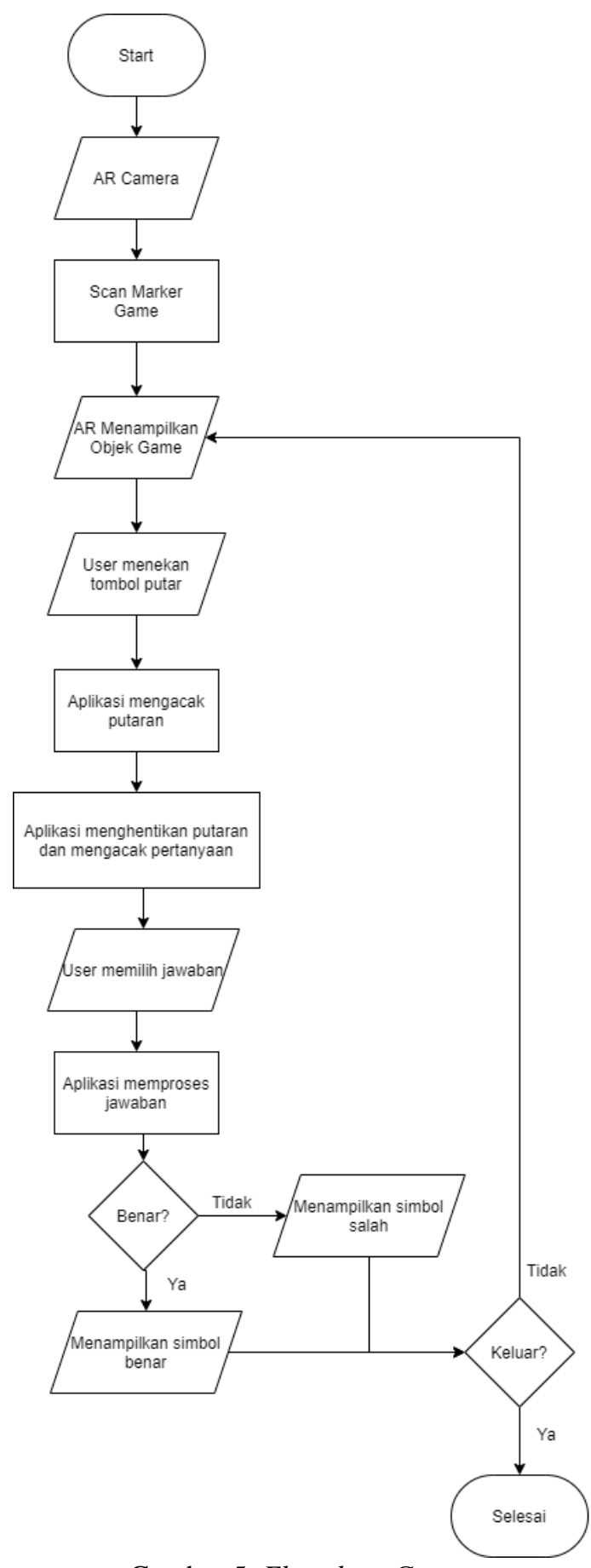

Gambar 5. Flowchart Games

\section{IMPLEMENTASI DAN PEMBAHASAN}

\section{Implementasi}

Pada tahap ini akan dijelaskan bagian-bagian layout program.

\section{Layout Splash Screen}

Splash Screen adalah tampilan atau animasi yang akan muncul ketika aplikasi dijalankan. Hal ini dapat dilihat pada Gambar 6. 


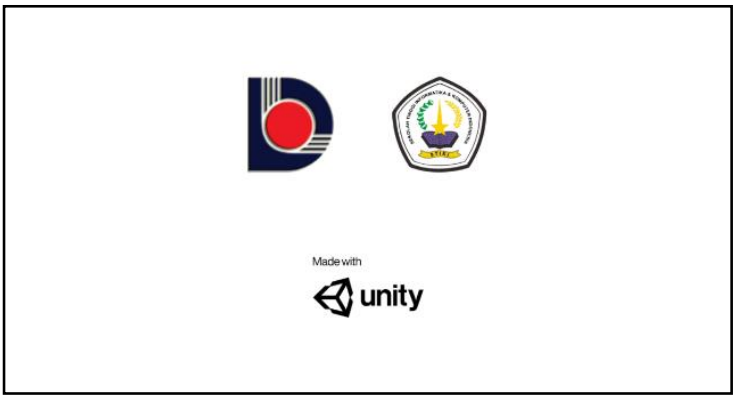

Gambar 6. Layout Splash Screen

\section{Layout Main Menu}

Menu utama berisi tombol tombol yang dapat ditekan dan akan menjalankan fungsinya masing masing. Tombol Scan Book berfungsi untuk membuka kamera AR dan tombol About berfungsi menampilkan detail tentang aplikasi. Layout Main Menu pada aplikasi ini dapat dilihat pada Gambar 7.

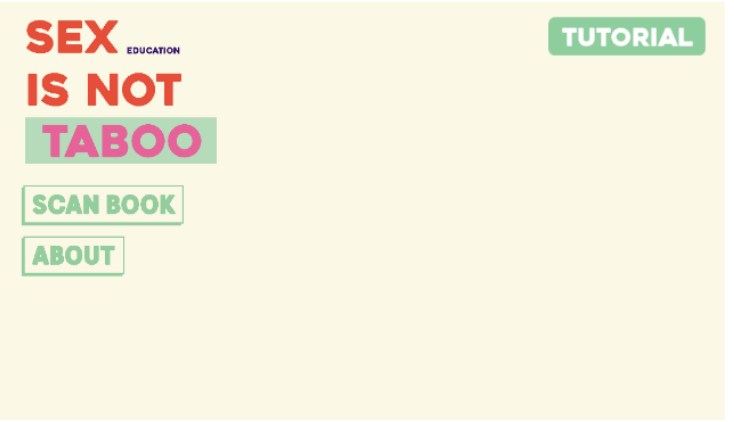

Gambar 7. Layout menu utama

\section{Layout Menu About}

Menu About berisi tentang detail aplikasi, pencipta dan juga penerbit aplikasi. Layout menu About dapat dilihat pada Gambar 8.

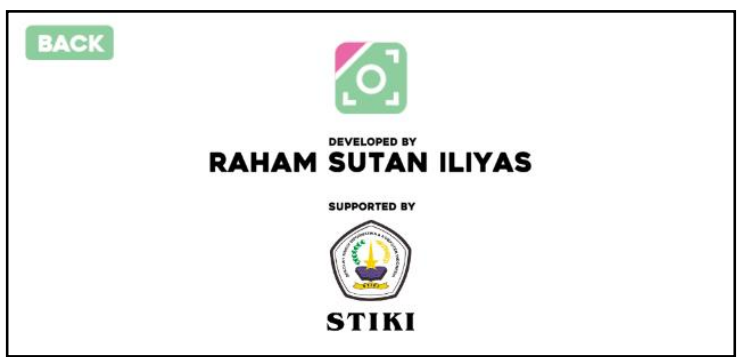

Gambar 8. Layout Menu About

\section{Layout Utama Kamera AR}

Kamera AR adalah fitur utama dari aplikasi. Pada Layout ini pengguna dapat memindai marker dan menampilkan objek AR pada layar handphone. Layout utama kamera AR dapat dilihat pada Gambar 9.

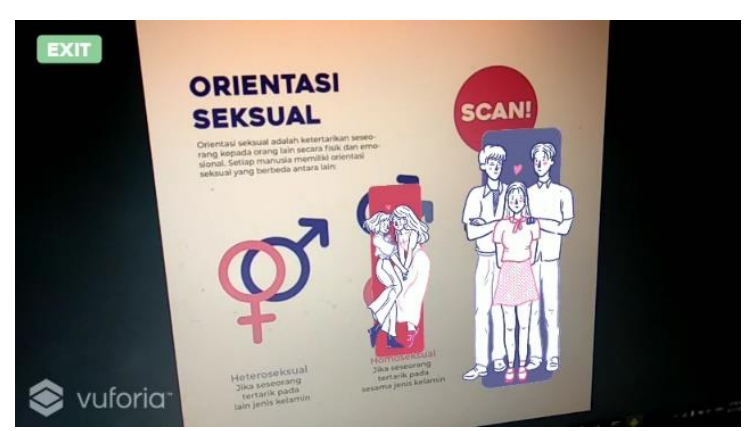

Gambar 9. Layout utama kamera AR

\section{Layout Interaksi Slide Gambar}

Setiap halaman buku telah disediakan interaksi antar halaman sebagaimana pada Gambar 10, dimana pengguna dapat menggunakan menu swipe ke kiri untuk ke halaman sebelumnya dan swipe ke kanan untuk ke halaman selanjutnya.

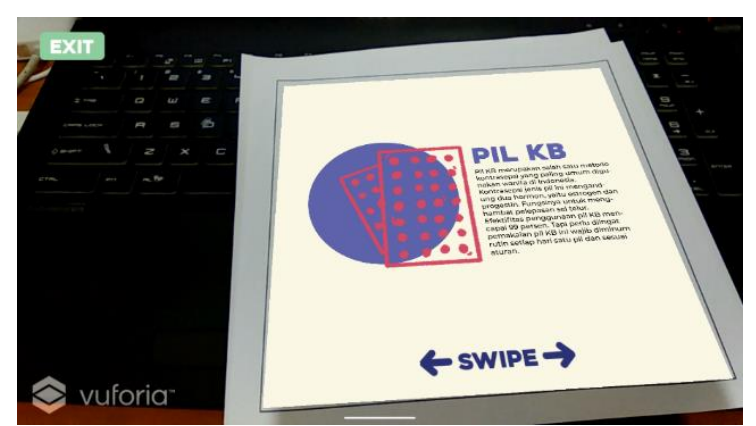

Gambar 10. Marker dan Objek yang Menggunakan Interaksi Slide

\section{Layout Interaksi Message Box}

Masing-masing halaman buku telah disediakan juga pesan interaktif. Jika pengguna tidak memahami istilah-istilah yang ada dalam buku ilustrasi. Contoh pesan interaktif sebagaimana pada Gambar 11.

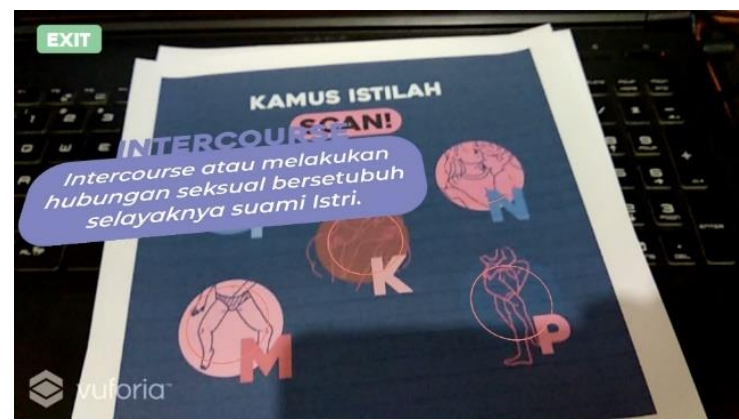

Gambar 11. Marker dan Objek yang Menggunakan Interaksi Message Box

\section{Layout Pada Marker Perubahan Fisik}

Pada bagian materi perubahan fisik, pada buku telah ditambahkan marker untuk menampilkan pesan buku yang interaktif. Penambahan marker pada buku ilustrasi dapat dilihat pada Gambar 12 dan Gambar 13. 


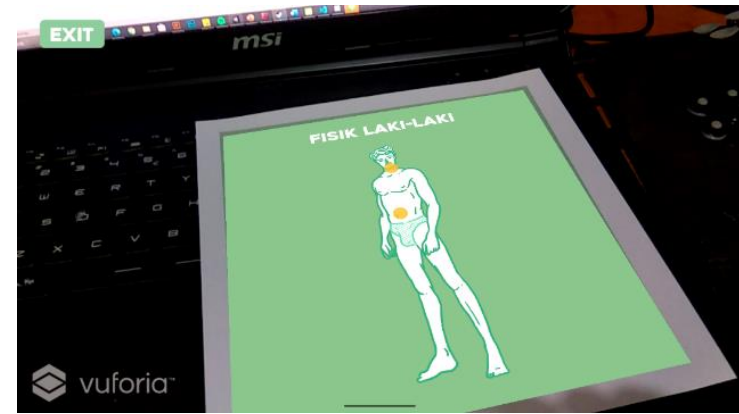

Gambar 12. Marker dan Objek Perubahan Fisik Sebelum Menekan Tombol Interaksi

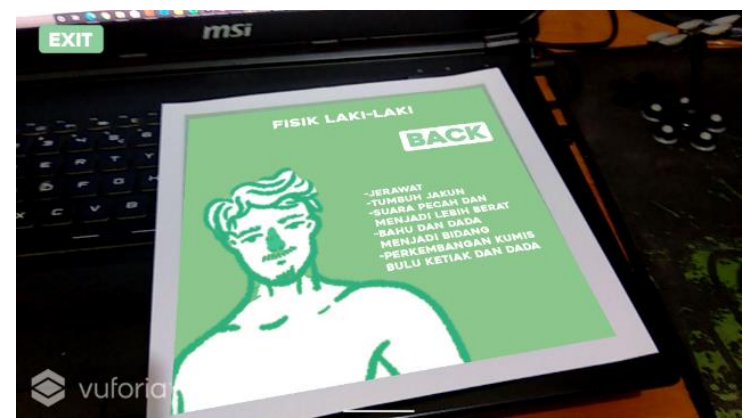

Gambar 13. Marker dan Objek Perubahan Fisik Sesudah Menekan Tombol Interaksi

Script ini berfungsi untuk mengatur semua interaksi pada kamera AR pada marker Perubahan Fisik seperti pada contoh Gambar 12 dan Gambar 13. Segmen ini memiliki Update(): fungsi default dari Unity, dimana dia akan menjalankan script pada setiap frame. Pada segmen ini berfungsi untuk mendeteksi sentuhan pengguna apakah menyentuh tombol sesuai dengan nama yang sudah ada atau tidak. Apabila sesuai maka akan menampilkan animasi sesuai dengan tombol yang sudah ditentukan.

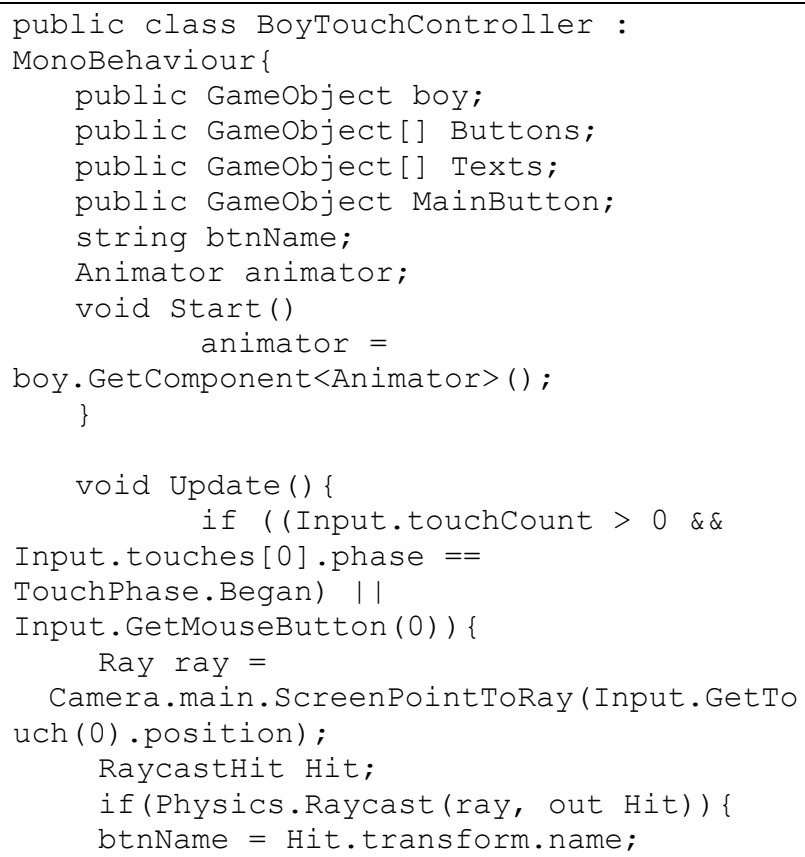

Segmen 1. Segmen Interaksi Pada Marker Perubahan Fisik

\section{Layout Pada Marker Siklus Menstruasi}

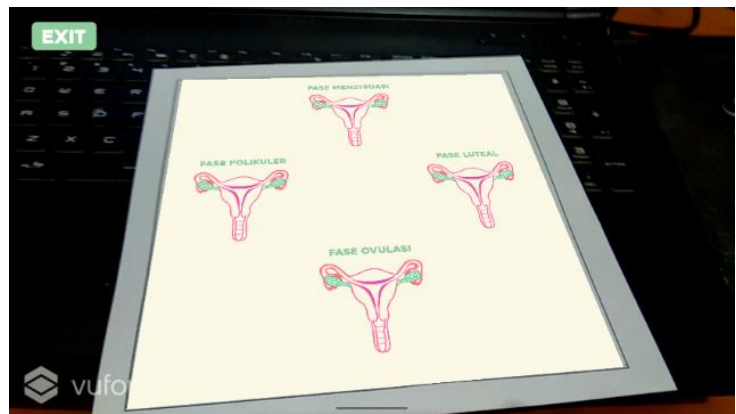

Gambar 14. Marker dan Objek Menstruasi

\section{Layout Pada Marker Game}

Penambahan mini game dalam buku ilustrasi untuk mengukur pemahanan pengguna setelah membaca materi pada buku ilustrasi. Gambar 15 menunjukkan mini game yang disediakan dalam buku.

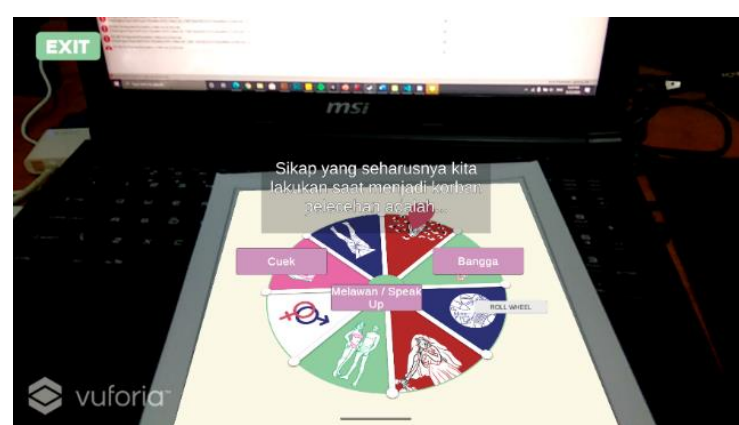

Gambar 15. Marker dan Objek Game 


\section{Pengujian}

\section{Pengujian Data Marker}

Pengujian ini akan menguji tingkat sensitivitas marker terhadap kamera AR. Pengujian marker telah dilakukan secara otomatis melalui website Vuforia Engine ketika pengguna meng-upload data marker untuk dijadikan database. Pengujian tersebut dilakukan dengan cara mencari karakteristik dari bentuk gambar yang di-upload dan diberi rating.

\section{Rating Rendah}

Pada Vuforia Engine apabila gambar marker mendapatkan rating rendah maka tingkat sensitivitasnya akan rendah ketika dipindai oleh kamera AR. Gambar 16 adalah contoh dari pengujian menggunakan gambar marker dengan rating rendah.

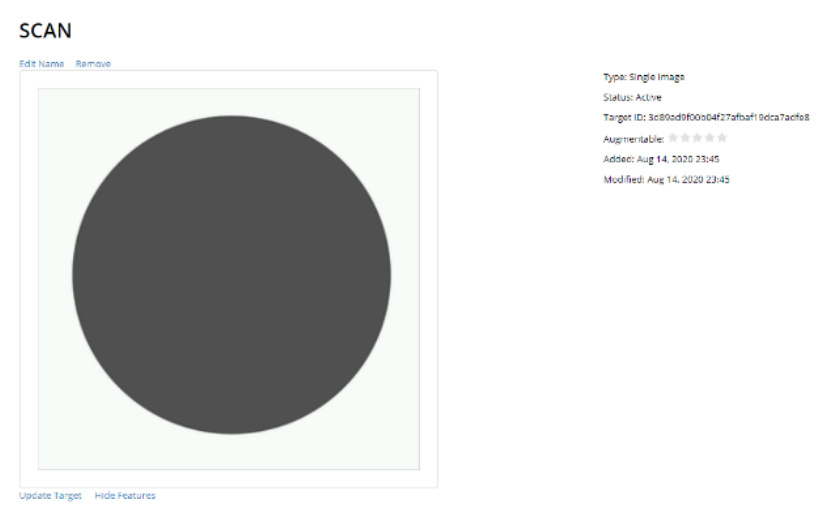

Gambar 16. Gambar Marker Dengan Rating Rendah

\section{Rating Tinggi}

Pada Vuforia Engine apabila gambar marker mendapatkan rating tinggi maka tingkat sensitivitas akan tinggi ketika dipindai oleh kamera AR. Gambar 17 adalah contoh dari pengujian menggunakan gambar marker dengan rating tinggi.

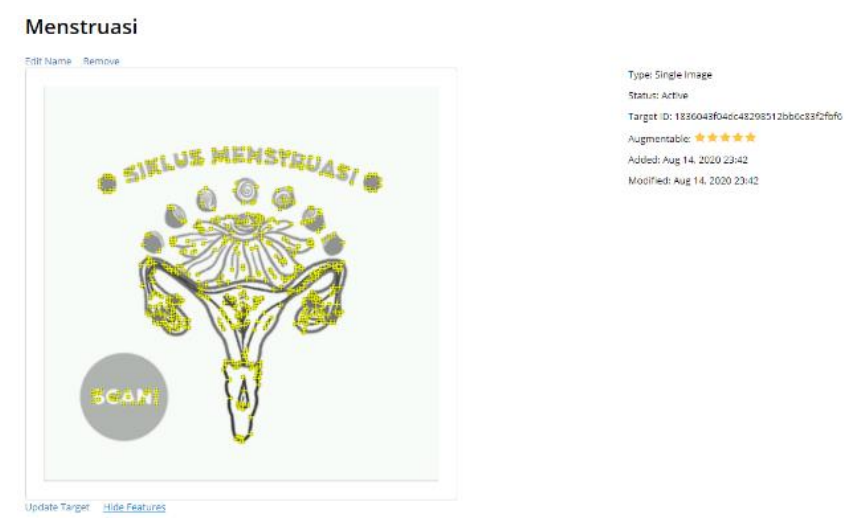

Gambar 17. Gambar Marker Dengan Rating Tinggi

\section{Pengujian Aplikasi}

Pada tahap ini akan dilakukan pengujian pada aplikasi. Pengujian di antaranya adalah untuk respon uji jarak dan sudut dari marker ke pemindaian kamera AR.
Pengujian jarak kamera dan marker dilakukan untuk mengetahui seberapa jauh dan seberapa dekat jarak kamera ke marker untuk dapat memindai marker dengan baik, Pengujian dilakukan pada sudut $90^{\circ}$ atau lurus dengan marker. Karena penghitungan jarak akan lebih mudah dan lebih konsisten bila diambil secara manual dari sudut ini.

Tabel 2. Hasil Pengujian Jarak

\begin{tabular}{|c|c|c|c|c|c|c|}
\hline \multirow{2}{*}{ Marker } & \multicolumn{6}{|c|}{ Jarak } \\
\hline & $5 \mathrm{~cm}$ & $10 \mathrm{~cm}$ & $15 \mathrm{~cm}$ & $20 \mathrm{~cm}$ & $25 \mathrm{~cm}$ & $30 \mathrm{~cm}$ \\
\hline Boy & Tidak Valid & Valid & Valid & Valid & Valid & Valid \\
\hline Faktor & Tidak Valid & Valid & Valid & Valid & Valid & Valid \\
\hline Games & Tidak Valid & Valid & Valid & Valid & Valid & Valid \\
\hline Girl & Tidak Valid & Valid & Valid & Valid & Valid & Valid \\
\hline $\begin{array}{l}\text { Kamus } \\
\text { Istilah }\end{array}$ & Tidak Valid & Valid & Valid & Valid & Valid & Valid \\
\hline Kontrasepsi & Tidak Valid & Valid & Valid & Valid & Valid & Valid \\
\hline Menstruasi & Tidak Valid & Valid & Valid & Valid & Valid & Valid \\
\hline $\begin{array}{l}\text { Orientasi } \\
\text { Seksual }\end{array}$ & Tidak Valid & Valid & Valid & Valid & Valid & Valid \\
\hline Pelecehan & Tidak Valid & Valid & Valid & Valid & Valid & Valid \\
\hline Pengobatan & Tidak Valid & Valid & Valid & Valid & Valid & Valid \\
\hline Penis & Tidak Valid & Valid & Valid & Valid & Valid & Valid \\
\hline Penyakit & Tidak Valid & Valid & Valid & Valid & Valid & Valid \\
\hline Vagina & Tidak Valid & Valid & Valid & Valid & Valid & Valid \\
\hline
\end{tabular}

Dari hasil pengujian jarak kamera pada marker dapat disimpulkan bahwa pada jarak $5 \mathrm{~cm}$ marker akan sulit terbaca karena terlalu dekat sehingga objek tidak muncul sama sekali. Sedangkan pada jarak $10 \mathrm{~cm}-20 \mathrm{~cm}$ marker akan terbaca lebih mudah dan tulisan pada objek terlihat dengan jelas. Pada jarak lebih dari $25 \mathrm{~cm}$ marker terbaca dan objek tampil, akan tetapi terkadang tidak pada posisi yang tepat atau bahkan objek terkadang menghilang.

\section{Pengujian Sudut}

Pengujian sudut kamera dan marker untuk mengetahui titik sudut kamera yang optimal dalam mendeteksi marker. Pengujian dilakukan pada jarak $15 \mathrm{~cm}$, karena pada jarak ini marker dapat terbaca dengan baik dan objek terlihat dengan baik.

Tabel 3. Hasil Pengujian Sudut

\begin{tabular}{llcccc}
\hline \multirow{2}{*}{ Marker } & \multicolumn{5}{c}{ Sudut } \\
\cline { 2 - 5 } & Tidak Valid & Valid & Valid & Valid & Valid \\
\hline Boy & Tidak Valid & Valid & Valid & Valid & Valid \\
\hline Faktor & Tidak Valid & Valid & Valid & Valid & Valid \\
\hline Games & Tidak Valid & Valid & Valid & Valid & Valid \\
\hline Girl & Tidak Valid & Valid & Valid & Valid & Valid \\
\hline Kamus & & & & & \\
Istilah & Tidak Valid & Valid & Valid & Valid & Valid \\
\hline Kontrasepsi & Tidak Valid & Valid & Valid & Valid & Valid \\
\hline Menstruasi & Tidak Valid & Valid & Valid & Valid & Valid \\
\hline Orientasi & & & & & \\
Seksual & & & & \\
\hline Pelecehan & Tidak Valid & Valid & Valid & Valid & Valid \\
\hline Pengobatan & Tidak Valid & Valid & Valid & Valid & Valid \\
\hline Penis & Tidak Valid & Valid & Valid & Valid & Valid \\
\hline Penyakit & Tidak Valid & Valid & Valid & Valid & Valid \\
\hline Vagina & Tidak Valid & Valid & Valid & Valid & Valid \\
\hline
\end{tabular}

\section{Pengujian Jarak}




\section{KESIMPULAN DAN SARAN}

\section{Kesimpulan}

Buku ilustrasi media interaktif berbasis Augmented Reality ini dapat dijadikan media alternatif untuk mengenalkan edukasi seks, karena buku ini selain interaktif juga memanfaatkan teknologi Augmented Reality. Pemanfaatan teknologi Augmented Reality berhasil dilakukan dalam pengaplikasian pada media buku ilustrasi. Aplikasi ini juga menambahkan nilai interaktif baru dengan bentuk game dalam mengulas materi yang sudah disampaikan buku ilustrasi. Diharapkan dengan adanya media ini, menyampaikan informasi tentang edukasi seks menjadi lebih mudah dan menarik untuk orang tua atau instansi yang membutuhkan. Media yang dihasilkan berbentuk aplikasi Android menggunakan Augmented Reality.

\section{Saran}

Media interaktif untuk buku illustrasi berbasis Augmented Reality ini diharapkan dapat membantu menyampaikan informasi edukasi seks dengan mudah dan penyampaian yang menarik. Media ini juga diharapkan agar bisa dikembangkan lagi di kemudian hari oleh penulis lain dengan media buku yang lebih beragam. Teknologi yang lebih interaktif dengan menambahkan animasi pada media Augmented Reality, menggunakan metode crop untuk pembuatan marker, dan juga dapat mengembangkan game dengan menggunakan bank soal.

\section{REFERENSI}

[1] Fleisman, M. (2004). Exploring Illustration. Thomson Delmae Learning.

[2] Rumajar, R., Lumenta, A.S.M. \& Sugiarso, B.A. (2015). Perancangan Brosur Interaktif Berbasis Augmented
Reality. Jurnal Teknik Elektro dan Komputer, Vol.4(6), pp. 1-9.

[3] Dhiyatmika, I.D.G.W, Putra, I.K.G.D. \& Mandenni, N.M.I.M. (2015). Aplikasi Augmented Reality Magic Book Pengenalan Binatang untuk Siswa TK. Lontar Komputer, Vol. 6(2), pp. 120-127.

[4] Putra, F.F., Juni, N.S. \& Rahmat, S. (2012). Aplikasi Pembelajaran Metamorfosis Berbasis Augmented Reality. Jurnal Teknik Informatika, Vol. 1.

[5] Sugianto, D.S., Oslan, Y. \& Kristanto, H. (2013). Computer Aided Instruction Untuk Pembelajaran Pengenalan Bentuk Untuk Anak Prasekolah Berbasis Augmented Reality. Jurnal Eksplorasi Karya Sistem Informasi dan Sains, Vol. 6(1).

[6] Djaouti, D., Alvarez, J., Jessel, J.P., Methel, G. \& Molinier, P. (2008). A Gameplay Definition through Videogame Classification. International Journal of Computer Games Technology, Vol 2008.

[7] Anindita, D.S., et.al. (2019). Modul Pendidikan Sebaya "Rencanakan Masa Depanmu”. Direktorat Bina Ketahanan Remaja BKKBN 2019.

[8] Fujiati, F. (2016). Perancangan Pengembangan Game Ular Melawan Ulat Menggunakan Augmented Reality Eksplora Informatika, Vol.6(1).

[9] Putra, R.W., Darlis, H., \& Imam, K. (2016) Permainan Augmented Reality dalam Mendukung Pembelajaran Anak tentang Binatang pada Perangkat iOS. Jurnal Teknik ITS, Vol. 5(2).

[10] Roedavan, R. (2014). Unity Tutorial Game Engine. Bandung: Penerbit Informatika.

[11] Fernando, M. (2013). Membuat Aplikasi Android AR Menggunakan Vuforia SDK dan Unity. Solo.

[12] Rizki, Y. (2012). Markerless Augmented Reality Pada Perangkat Android [Paper]. 